\title{
LA CONDUCTA DE LA VÍCTIMA COMO CLAVE PARA UN SISTEMA DE LOS DELITOS PATRIMONIALES QUE LLEVAN CONSIGO SUSTRACCIÓN*
}

\author{
Joachim Hruschka \\ Catedrático de Derecho penal y Filosofía del Derecho \\ Universidad de Erlangen-Nürnberg
}

\section{El problema}

El Código penal Alemán (StGB) distingue, como es sabido, entre hurto [Diebstahl], estafa [Betrug] y extorsión [Erpressung] y además entre robo [Raub] y extorsión agravada [räuberische Erpressung]. Por lo que se refiere a los elementos del tipo objetivo, el hurto se caracteriza por la toma de una cosa mueble ajena, donde "tomar», según la doctrina general de la bibliografía autorizada, significa "ruptura de la posesión ajena e instauración de una nueva sobre la cosa en cuestión" ${ }^{2}$. Estafa es, también según la opinión general, el engaño a una persona, que le hace caer en un error por cuyo motivo lleva a cabo un acto de disposición patrimonial experimentando así un perjuicio patrimonial. También un tercero puede sufrir un perjuicio patrimonial, si el engañado dispone del patrimonio de aquél ${ }^{3}$. Comparando los elementos de la extorsión con los del tipo de la estafa, aquélla consiste en el empleo de violencia o amenaza de un mal relevante, en virtud de las cuales el afectado se ve en una situación de necesidad, ante la que lleva a cabo un acto de disposición patrimonial experimentando así un perjuicio patrimonial. También aquí es posible que un tercero experimente un perjuicio, si el afectado realiza un acto de disposición sobre el patrimonio de aquél. Podría entenderse que esta interpretación de la extorsión se corresponde con la opinión

\footnotetext{
*Traducción de "Das Opferverhalten als Schlüssel zum System der Sachentziehungsdelikte", en Jahrbuch für Recht und Ethik, vol. II (1994), pp 177-190, a cargo de Pablo Sánchez-Ostiz. Titular de Derecho penal. Universidad Pompeu Fabra. Agradezco las observaciones realizadas a esta traducción por Jan Schuhr, asistente de la cátedra de Derecho penal, Derecho procesal penal y Filosofía del Derecho en la Universidad de ErlangenNürnberg.

1§ 242 । StGB: [hurto] "Quien toma una cosa mueble ajena de otro con la intención de apropiársela antijurídicamente, será castigado...". [La 6. Ley de reforma penal, de 26 de enero de 1998, modificó los preceptos citados en algunos extremos; por este motivo se facilita también el texto de los preceptos reformados, cuando ello es de interés a los efectos de este trabajo, señalando en letra cursiva las variaciones introducidas: "Quien toma una cosa mueble ajena de otro con la intención de apropiársela él o un tercero antijurídicamente. será castigado..." (N. del T.)]

${ }^{2}$ Cfr. por ejemplo LACKNER, StGB mit Erläuterungen, 20. ${ }^{2}$ ed., 1993, § 242, núm. marg. 8.

${ }^{3} \S 263$ । StGB: [estafa] "Quien con la intención de conseguir para sí o para un tercero una ventaja patrimonial antijurídica, produce un perjuicio a otro en su patrimonio provocando o manteniendo un error, por simulación de algo falso o por deformación o supresión de hechos verdaderos, será castigado...".
} 
dominante hoy día en la bibliografía jurídico-penal ${ }^{4}$. Según el tenor de la ley $-y$ la doctrina hoy dominante-, un hurto pasa a ser robo y una extorsión se agrava [sancioná ndose como robo], si el hecho se lleva a cabo empleando violencia contra una persona o intimidación, con un peligro actual para la integridad física o la vida ${ }^{5}$.

Por consiguiente, el Derecho penal alemán distingue, como específicos delitos que llevan consigo sustracción de cosas: el hurto, que puede pasar a ser robo; y además, también dentro de aquella misma categoría, la extorsión referida a cosas, que puede pasar a ser extorsión agravada ly sancionarse entonces como robo violento o intimidatorio]; y la estafa sobre cosas. Cuando los delitos de extorsión y estafa recaen sobre cosas nos hallamos ante sendos supuestos de aplicación, caracterizados por existir un acto de disposición patrimonial por parte de la víctima al disponer sobre la tenencia de una cosa; o bien — según la terminología acostumbrada en el hurto- al disponer sobre la posesión de la cosa, pues ya la simple tenencia de una cosa es un elemento integrante del patrimonio sobre la que puede disponerse. Los tipos de extorsión y estafa comprenden, claro está, otros supuestos además de los que se refieren a cosas.

Los delitos patrimoniales que llevan consigo sustracción, como el hurto, estafa sobre cosas y extorsión, se caracterizan porque un tenedor de la posesión pierde, a través del delito, la posesión sobre una cosa. Por esto, la apropiación indebida de cosas [Unterschlagung] no forma parte de los delitos que llevan consigo sustracción, porque éstos son sólo aquellos cuyo tipo presupone una pérdida de la posesión para el hasta entonces tenedor de la posesión; no por que se encuentre junto a un hecho de tal género pasa la apropiación indebida a ser un delito de sustracción ${ }^{6}$. Con frecuencia, la pérdida de la posesión que experimenta la víctima viene acompañada de la obtención de la posesión de la cosa por un tercero, por lo general, el autor. Sin embargo, la

\footnotetext{
§ 253 I: [extorsión] "Quien coacciona antijurídicamente a otro, con violencia o con intimidación de un mal relevante, a actuar, tolerar u omitir, y ocasiona así una pérdida en el patrimonio del coaccionado o de un tercero. para enriquecerse injustamente él o un tercero, será castigado...".

5 $\$ 249$ I: [robo] "Quien, con violencia contra una persona o empleando intimidación mediante un peligro actual para la integridad física o la vida, toma una cosa mueble ajena de otro con la intención de apropiarse de ella antijurídicamente [él o un tercero], será castigado...". § 255: "Si la extorsión se realiza con violencia contra una persona o con la aplicación de intimidación con un peligro actual para la integridad o la vida, entonces se sancionará al autor igual que al del robo." [El tipo de la Erpressung del § 253 no es idé ntico a la extorsión del art. 243 CP. El $§ 255$ define la conducta de räuberische Erpressung como tipo cualificado: la violencia o intimidación empleadas suponen un peligro actual para la vida o integridad, en cuyo caso la conducta se sanciona como robo. Algunas conductas que en España se consideran robo violento o intimidatorio (por ejemplo, las seguidas de entrega de la cosa por la propia victima amedrentada) constituyen Erpressung según el § 253. Debe tenerse en cuenta este matiz cuando en la traducción se emplea el término extorsión. (N. del T.)].

Tras la nueva versión del § 246, el tipo de la apropiación indebida puede ser integrado con el del hurto. El § 246 StGB define la apropiación indebida como "apropiación de una cosa mueble ajena". El inciso "que el autor haya recibido en tenencia o posesión" fue suprimido en la nueva versión del precepto. [El contenido de esta nota y de la frase del texto a la que viene a completar, fueron modificadas de acuerdo con el autor. (N. del T.)]
} 
obtención de la posesión a través de un tercero, como dicho tenedor de la posesión, no forma parte del concepto de delito patrimonial con sustracción de cosas.

Además, todo delito de esta clase se caracteriza porque el autor de alguna manera determina o codetermina la pérdida de la posesión, porque en verdad "sustrae» la cosa a la víctima. La conducta puede definirse por medio de ulteriores elementos; el autor puede así emplear violencia o intimidación de un mal relevante, o bien recurrir a la astucia como medio comisivo. Otra diferencia específica entre las diversas modalidades de delitos patrimoniales de sustracción viene dada por el modo de la eventual participación de la víctima en la pérdida de la posesión sufrida. La víctima puede no tomar parte en la desposesión; o puede en cambio participar, sea aportando algo de forma activa, sea tolerándola.

Los intentos hasta ahora realizados para construir un sistema acabado de los delitos de sustracción de cosas parten de la actual regulación de los tipos recogida en los $\S \S 242$ (hurto), 263 (estafa), 253 (extorsión), 249 (robo) y 255 (extorsión agravada, sancionada como robo). Se procede a «interpretar" los tipos "delimitando" entre unos y otros. Pero el defecto de un método así es palmario. Hurto, estafa y los restantes delitos, tal y como hoy los conocemos, son resultado provisional de una evolución histórica. Al contemplar dicha evolución, de inmediato se aprecia cómo los tipos actuales se han formado de manera separada unos de otros ${ }^{7}$. Por eso, no está justificado prescindir de esas diferencias y separaciones entre los tipos al construir un sistema de los delitos de sustracción. En la medida en que partamos de los tipos del StGB hoy vigente, conseguiremos a lo sumo aproximarnos a un sistema. Así el grado de aproximación al sistema dependerá de cuánto se haya ido acercando a éste la evolución de los tipos hasta el momento ${ }^{8}$. En los métodos de trabajo que son hoy usuales, nos hallamos condicionados por el curso de la historia del Derecho hasta nuestros días. Y como los resultados alcanzados hasta ahora en la evolución de la historia del Derecho son provisionales, ello ha de afectar necesariamente a nuestras investigaciones.

El presente trabajo sigue otro camino. Su objeto consiste en cierto modo en efectuar una reconstrucción racional del sistema de los delitos de sustracción, producto

\footnotetext{
7 Sobre el desarrollo histórico, incluyendo los conceptos del Derecho romano de furtum, stellionatus y concussio, cfr. Hermann-BLel, Strafrecht Besonderer Teil, 12." ed., München, 1983, pp 169, 215 y $249 \mathrm{~s}$.

La idea es una obviedad; y por eso hace ya mucho tiempo que ha sido tenida en cuenta. Cfr. únicamente August HEGLER, "Das System der Vermögensdelikte», en Archiv für Rechts- und Wirtschaftsphilosophie IX (1915/1916). p 153 s5; 154. Otros trabajos de importancia sobre nuestro tema son: Horst SCHRODER, "Über die Abgrenzung des Diebstahls von Betrug und Erpressung», en ZStW 60 (1941), p 33 ss; Harro OTTO, «Zur Abgrenzung von Diebstahl, Betrug und Erpressung bei der deliktischen Verschaffung fremder Sachen", en ZStW79 (1967), p 59 ss; el mismo, Die Struktur des strafrechtlichen Vermögensschutzes, 1970; Rolf Dietrich HERzBERG, “Betrug und Diebstahl durch listige Sachverschaffung», en ZStW 89 (1977), p 367 ss; cfr, también, más recientemente, Rudolf SCHMITT, "Nehmen oder Geben, ist das hier die Frage?», en Manfred SEEBODE (ed.). Festschrift für Günter Spendel, Berlin, 1992, p 575 ss.
} 
de lo que se percibe en el transcurso de la historia del Derecho. Dicho de otro modo: se expone cómo en los delitos de desposesión (hurto y robo, extorsión y extorsión agravada y estafa de cosas) subyacen estructuras prepositivas, de cuyo análisis se trata en lo que sigue.

\section{Las estructuras de imputación como medio de análisis}

Elementos para el análisis son las diferenciaciones existentes entre imputatio facti, applicatio legis ad factum e imputatio iuris; entre imputación ordinaria y extraordinaria; y entre cuatro motivos distintos que excluyen la imputación ${ }^{9}$. iuris ${ }^{10}$

1. La diferenciación entre imputatio facti, applicatio legis ad factum e imputatio

a) Lo primero de todo, han de diferenciarse la aplicación de una ley (lex) a un hecho (factum) y la imputación de ese hecho. Ambos constituyen actos de juicio. También KANT, en conexión con Christian WOLF, califica de forma expresa la «imputación” como un «juicio». Sobre la relación entre ambos juicios, se lee en WOLFF" : "Ex applicatione legis ad factum intelligitur, actionem esse talem, quae imputari possit." ("de la aplicación de una ley a un hecho se pone de manifiesto que el hecho es un acontecimiento que puede ser imputado."). Dicho pasaje afirma que toda applicatio legis ad factum implica la imputabilidad del factum, al que la lex se aplica; lo cual viene a afirmar, como efecto final, la tesis de que una applicatio legis ad factum contiene siempre una imputatio facti. Una imputatio facti es así aquello que en KANT ${ }^{12}$ se denomina simplemente “imputación»: “Imputación (imputatio) es el juicio por el que alguien es visto como Urheber (causa libera) de una acción, que entonces se denomina hecho (factum)". Donde "Urheber (causa libera) de una acción" designa de manera clara al sujeto que actúa libremente. KANT: «imputamos (algo) cuando simpliciter es atribuido a una persona, esto es, cuando es concebido como originado en

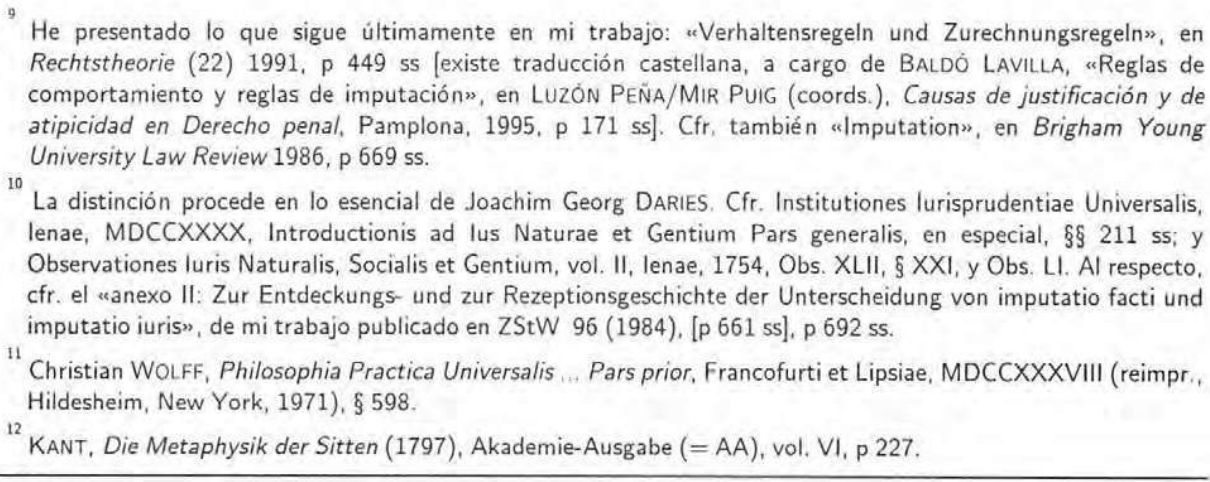


la libertad.” ${ }^{13}$. Expresado de otro modo: la imputación de un proceso o de una inactividad como "hecho (factum)" - de forma más precisa: como "realización de una acción» u "omisión de una acción»- equivale a aceptar por quien emite el juicio de imputación que la persona a la que él -el que emite el juicio - imputa la realización o la omisión como hecho disponía de una alternativa a ese hecho. La cita de WOLFF afirma así que en la aplicación de una ley a un hecho, quien emite el juicio - quien juzga - parte de la aceptación de que la persona a cuyo hecho se aplica la ley, tenía una alternativa a ese hecho ${ }^{14}$.

b) La imputatio iuris es el juicio sobre el mérito del hecho, en el amplio sentido de la palabra "mérito", que comprende tanto el positivo como el negativo. La aplicación de la ley a un hecho puede dar lugar a alguno de estos tres resultados: puede mostrar que la persona a cuyo hecho se aplica la ley: 1] ha obrado conforme a la ley (dicho de modo más exacto: conforme a la versión prospectiva de la ley aplicada); o 2] ha infringido la leyes; o 3] ha llevado a cabo más de lo que la ley requiere, es decir, ha obrado de manera supererogatoria. En el tercer caso se imputa el hecho supererogatorio "a mérito" (meritum); en el segundo se imputa el hecho antijurídico «a la culpabilidad" (demeritum): en estos casos la imputatio iuris es equivalente a alabanza o reproche. En el primer caso, por el contrario, la persona ha llevado a cabo precisamente su deber (debitum); siguiendo a PUFENDORF ${ }^{15}$ KANT $^{16}$, en este caso no tiene lugar ninguna imputatio iuris .

Si ha procedido un juicio de imputación de este género - una imputatio iuris-. ello significa que ya ha tenido lugar la aplicación de la ley (lex) al hecho. Por eso existe también aquí una relación de implicación: la imputatio iuris implica la aplicación de la lex al hecho. Así ya DARIES ${ }^{18}$ : "Mihi videtur", "quod hic actus (i.e. actus applicationis legis ad factum) imputationi iuris antecedat, et imputationi facti sequatur.» - A mi entender, el acto de aplicación de la ley precede a la imputatio iuris y sucede a la imputatio facti.» Por eso, podemos en adelante caracterizar a la imputatio facti

\footnotetext{
${ }^{13}$ KANT, AA, vol. XIX (Reflexionen zur Moralphilosophie), p 157, refl. 6775.

${ }^{14}$ La frase de Wolff constituye la versión retrospectiva del conocido " "deber" implica "poder "». Al hablar sin ironia y sin rodeos, afirmamos " "deber" implica "poder " cuando, por ejemplo, quien da una orden, pone de manifiesto al enunciarla, que quien la recibe se encuentra en condiciones de seguirla: la orden “icierra la puerta!n implica por tanto que quien ordena da por supuesto que quien la recibe puede en efecto también cerrar la puerta. Consecuentemente, toda applicatio legis ad factum implica la aceptación de que el suceso al que la ley se aplica puede ser imputado - como un factum, como hecho- al ser humano que en él se ve involucrado.

${ }^{15}$ Elementa lurisprudentiae Universalis, Hagae-Comitis, MDCLX, Lib. I, Def. XX ( $241 \mathrm{~s}$ ).

${ }^{16} A$, vol. 6, p $227 \mathrm{~s}$.

${ }^{17}$ Como tampoco hay motivo alguno para alabar o reprochar, si todos los días cumplo la norma "no debes matar".

${ }^{18}$ Institutiones, § 225 (escolio).
} 
también como "imputación de primer nivel» y a la imputatio iuris como «imputación de segundo nivels.

2. La diferenciación entre imputación ordinaria y extraordinaria ${ }^{19}$ :

Si no existe motivo alguno que excluya la imputación (enseguida trataremos de ello, infra 3), sea la de primer nivel, sea la de segundo nivel, entonces hablamos de «imputación ordinaria». Si, por lo contrario, sucede que la situación proporciona un motivo para excluir la imputación, y sin embargo a la persona a la que debe imputarse le hacemos responsable de encontrarse en esa situación (que excluye la imputación ordinaria), hablamos de «imputación extraordinaria». La terminología se adapta así al lenguaje en el que de forma generalizada se habla de «imputación». El lenguaje tradicional emplea la misma diferenciación, pero resalta el hecho imputado en lugar del juicio de imputación. El hecho imputado de forma ordinaria significa en la tradición "actio libera in se», esto es, "acción considerada en sí misma libre», mientras que el hecho imputado de forma extraordinaria significa "actio libera in (sua) causa", esto es, "acción libre en su causa".

3. Motivos en virtud de los cuales se excluye la imputación ordinaria, sea de primero, sea de segundo nivel: situación de necesidad y error ${ }^{20}$ :

1) Una "situación de necesidad absoluta", una "necessitas simplex seu absolutas" (DARIES ${ }^{21}$ ) excluye la imputación ordinaria de primer nivel. Eso significa que el tener o no lugar un evento físico, del que se trata en un caso concreto, no se imputa a la persona que en él se ve inmersa como «hecho", como "aportación de una acción» o, en su caso, como "omisión de una acción». Ejemplo: A golpea con intensa violencia ("vis absoluta") a B en el codo atravesando el vidrio de una ventana. La exclusión de la imputación ordinaria (la destrucción del vidrio de la ventana como conducta de daños materiales) se deriva de la regla "Impossibilium et necessariorum nulla est imputatio" $\left(\right.$ HUTCHESON ${ }^{22}$ ).

${ }^{19} \mathrm{Cfr}$. al respecto, HRUSCHKA, "Ordentliche und außerordentliche Zurechnung bei Pufendorf - Zur Geschichte und zur Bedeutung der Differenz von actio libera in causa in se und actio libera in sua causan, en ZStW 96 (1984), p 661 ss; "Probleme der actio libera in causa heuten, en JZ 44 (1989), p 310 ss

20

Cfr. al respecto, HRUSCHKA, «Rechtsfertigungs- und Entscheidigungsgründe: Das Brett des Karneades bei Gentz und bei Kant», en GA 138 (1991), p 1 ss; p 6 ss.

${ }^{21}$ Observationes luris Naturalis, Socialis et Gentium, vol. II, Obs. LI, p 166 ss.

22

En el Digesto 50,17,185 se atribuye a CELSUS “impossibilium nulla obligatio». En la consideración retrospectiva de un suceso corresponde el enunciado "impossibilium nulla imputation. HUTCHESON. A system of Moral Philosophy, posthum London MDCCLV, reimpr. B. Fabian (ed.), Collected Works of Francis Hutcheson, vol. V. 1969 , p. 229 , nota, caracteriza el enunciado reproducido en el texto como "common maxim". 
2) La imputación ordinaria de un suceso como «realización de una acción», y la imputación ordinaria de que no tenga lugar un evento como "omisión de una acción" (es decir, de nuevo: la imputación de primer nivel), quedan además excluidas también si la persona a la que debe imputarse el hecho desconoce las circunstancias que son relevantes para caracterizar el hecho a imputar. Casos de este género se denominan, de acuerdo con la tradición, "casos de una ignorantia facti». Ejemplo: A podría salvar a un sujeto que se está ahogando, si le lanza un salvavidas. Hay un salvavidas, y A podría también hacerse con él. Sin embargo, el salvavidas está oculto en la arena de la orilla, y A lo desconoce. También aquí rige la regla «/mpossibilium et necessariorum nulla est imputation, porque para A, a causa de su error, le resulta imposible utilizar el salvavidas para salvar a quien se ahoga.

3) Una "necessitas cum adiunctione" (DARIES), una situación de necesidad "con limitaciones" " puede excluir la imputación ordinaria en el segundo nivel. Lo cual significa que el hecho se considera en verdad como "hecho", y también es enjuiciado como antijurídico, pero no imputado a la "culpabilidad». Ejemplos de ello ofrecen los casos de una "vis compulsiva", de una amenaza con causar un mal relevante, y otros casos semejantes, como cuando $\mathrm{A}$, mostrando una pistola, compele a $\mathrm{B}$ a que maltrate a $C$ golpeándole. Sin embargo, excluir aquí la imputación de segundo nivel resulta tan evidente, como difícil fundamentarlo. Lo mejor es buscar una fundamentación en paralelo con la regla "Impossibilium et necessariorum nulla est imputatio», como KANT la entiende al tratar el caso de la tabla de Carnéades ${ }^{23}$. Aunque también podría ser que la propia formulación de KANT, según la cual, en una situación de necesidad de las que aquí se trata, una "ley penal» no puede «alcanzar de ningún modo» «el efecto pretendido" (i. e., hacer desistir de su hecho al autor) pareciera necesitada de mejoras.

4) Por último, la imputación ordinaria de un hecho antijurídico a la culpabilidad (asimismo, por tanto, en el segundo nivel de imputación) se excluye si el autor desconoce la norma que le prohibía o, en su caso, le prescribía la realización de la conducta. Estos son los casos de una ignorantia iuris. Ejemplo: el panadero infringe la prohibición de hacer uso del horno durante la noche, porque desconoce la norma que prohíbe ese trabajo durante noche. En los casos de esta índole es claro que la norma no puede tener "el efecto buscado» (a saber: hacer desistir de trabajar de noche al panadero).

Para completar lo expuesto, habría que añadir que en las constelaciones de casos 1) a 4) siempre puede entrar en consideración una imputación extraordinaria.

\footnotetext{
- Necessitas cum adiunctione significa situación de necesidad que no excluye actuar con volición, pero sí el actuar voluntariamente en el caso en cuestión: no puede decirse con propiedad que sea una situación de necesidad (pues, con rigor, situación de necessitas es la absoluta), pero por extensión se considera asi (N. del T.). 23 Die Metaphysik der Sitten, AA vol. 6, p 235 s.
} 
Para una imputación extraordinaria en los casos del número 2) se habla de “imprudencia». Los $\S \S 35.1$ (segundo inciso) StGB, con la claúsula de creación del peligro, y 17 (inciso 1), con la cláusula de evitabilidad, prevén una imputación extraordinaria". Sin embargo, sobre ello no se precisa aquí una exposición más detallada, dado que la imputación extraordinaria no desempeña ningún papel en las estructuras de los delitos patrimoniales que llevan consigo sustracción, de las que enseguida se tratará.

4. Igualmente, sólo puede hacerse referencia a que a ambos niveles de imputación corresponden sendos conceptos de libertad. La libertad de la que se trata cuando se imputan un suceso o inactividad como "realización» u "omisión de una acción» - como «hecho»-, es distinta de la libertad de la que se trata en relación a la imputación «a la culpabilidad». La diferencia se expresa en alemán también con la oposición de las expresiones willentlich ("con volición») y freiwillig ("voluntariamente»), que se corresponden con la existente entre "voluntad» [Wille] y "deseo" [Wunsch]". Quien obra "con [un acto de] volición" no siempre obra voluntariamente, pero quien obra "voluntariamente» sin duda obra "con volición». Resulta aquí oportuno también el adagio "quod quis agat, vel non agat, prout vult agere, vel non agere." Es decir, "lo que se hace, se quiere hacer; y lo que no se hace, no se quiere hacer." 24 .

\footnotetext{
*Expresa el § 35: «Estado de necesidad exculpante. (1) El que, ante un peligro actual, e inevitable de otro modo, para la vida, integridad o libertad, comete un hecho antijuridico para apartar un peligro de si mismo, de un pariente o de otra persona allegada, obra sin culpabilidad. Esto no rige en caso de que al autor, en función de las circunstancias, en particular por haber creado él mismo el peligro o porque se encuentre en una relación jurídica especial, pueda exigirsele hacer frente al peligro; no obstante, la pena podrá atenuarse conforme a lo dispuesto en el § 49, párrafo 1, si el autor había tenido que hacer frente al peligro, pero no en consideración a una relación jurídica especial. (2) ...n. Y el § 17 StGB: “Error de prohibición. Si al autor le falta, en el momento de cometer el hecho, el conocimiento de estar obrando antijurídicamente, actúa sin culpabilidad siempre que no haya podido evitar dicho error. Si lo hubiera podido evitar, cabrá atenuar la pena conforme a los dispuesto en el § 49, párrafo 1.". Versión extraída de SILVA SÁnCHEZ, Anexo a El sistema moderno del Derecho penal: cuestiones fundamentales, Madrid, 1991, pp 196-197 (N. del T.).

*Los términos del original (willentlich y freiwillig) han sido traducidos respectivamente como "con volición" y "voluntariamente", tanto en este texto, como en "Prohibición de regreso y concepto de inducción. Consecuencias". En este último (en Revista de Derecho Penal y Criminología, enero 2000, $n^{2}$ 5, p 210, nota ****), se explica cómo los grupos de casos (1) y (2) en los que se aprecia un actuar no willentlich, podrían calificarse también con la expresión castellana "sin querer", pero no siempre resulta idónea en este contexto. A pesar de las referencias a "desire" y "Wunsch", no se ha traducido como "deseo", para mantener el paralelismo de las raíces de los términos empleados, y porque el autor, pudiendo hacerlo, no emplea Wunsch directamente. Cfr. nota siguiente ( $\mathrm{N}$ del T.)

24

${ }^{24}$ Encuentro el adagio en Gershom CARMICHAEL, en el comentario a PUFENDORF, De Officio Hominis et Civis, editio secunda Edinburgi MDCCXXIV, Lib. I, Cap. I, § 10, nota 1. Alli Carmichael remite a LOCKE, que en An Essay Concerning Human Understanding (1690; 4. ${ }^{3}$ ed., 1700). Book II, Chap. XXI, § 30 (ed. Peter H. Nidditch, Oxford, 1979, p 249 s), establece más exactamente que habría que distinguir entre "willing" y "volition", por un lado, y "desire" por otro. De forma muy adecuada hay que distinguir también en alemán entre "Wille" y el mero "Wunsch"; cfr. también KANT, Grundlegung zur Metaphysic der Sitten, AA, vol. VI, p 213.
} 
Actúa "con volición", aun cuando no "voluntariamente», quien se ve compelido a actuar en una situación de necesidad del número 3), mientras que quien se halla en una situación de necesidad del número 1) en absoluto «actúa» (en el significado actual del término), es decir tampoco tiene "volición». También la persona que no encuentra el salvavidas - cfr. supra 2) - permanece pasiva sin un acto de «volición» en lo que a la salvación del que se ahoga se refiere. En los casos del número 4) la acción transgresora de la norma ignorada (en el ejemplo, la transgresión de la prohibición de hacer pan por la noche), no se realiza "voluntariamente".

\section{Aplicación de estos criterios a los delitos patrimoniales que llevan consigo sustracción}

¿Qué aportan estas diferenciaciones al problema que nos ofrecen los delitos patrimoniales que llevan consigo sustracción? La idea básica que deseo presentar aquí es sencilla. Las estructuras de imputación tal y como ahora han sido expuestas, se refieren al autor de un hecho. Se trata de trasplantar el modelo hallado para el autor a la víctima de la acción delictiva en los delitos patrimoniales que llevan consigo sustracción.

Las siguientes consideraciones parten de la premisa de que no es posible hablar de un delito patrimonial que lleva consigo sustracción si la pérdida de la cosa debe imputarse de forma plena al anterior tenedor de la posesión. El panadero que por la mañana vende sus panecillos al fin y al cabo pierde la posesión de éstos. Sin embargo, aunque el cliente sin duda determina -0 en cualquier caso co-determina- que el panadero pierda la posesión sobre los panecillos comprados, no realiza ningún delito patrimonial de sustracción. $Y$ ello porque la pérdida de los panecillos es plenamente imputable al panadero, que los entrega sin violencia ni error. El panadero obra con volición y voluntariamente. No es posible una sustracción delictiva por parte del comprador.

Lo mismo ha de valer si el tenedor de la posesión tolera la pérdida y dicho tolerar se realiza sin violencia ni error. Si el panadero observa y deja que una persona le quite un panecillo, aunque sin dificultad podría impedir esa pérdida de la posesión, llevarse de la panadería el panecillo no constituye ningún delito (consumado) de sustracción. El panadero obra con volición — «quod quis agat, vel non agat, prout vult agere, vel non agere»- y voluntariamente, y por consiguiente está de «acuerdo», en el sentido técnico de la palabra, con la transmisión de la posesión. Claro que, haciendo muchas reservas mentales, igual desea explicarnos que él no consentía en transmitir la posesión; - que está indignado porque haya un sinvergüenza capaz de llevarse un panecillo sin decirle nada; o también que tiene motivos éticos muy elevados para no atacarle. Pero nada de eso varía su estar de acuerdo. A la vista de que voluntariamente ha aprobado 
la pérdida de la posesión, cualquier explicación de lo contrario sería un simple venire contra factum proprium, una autocontradicción que nada variaría el hecho de haber tolerado sin violencia ni error esa transmisión de la posesión. Esto hoy en buena medida se reconoce ${ }^{25}$.

Distinto es si el hasta entonces tenedor de la posesión no toma parte en la pérdida de la posesión ni contribuyendo de forma activa, ni tolerando ante las circunstancias, o si su participación adolece de un defecto de imputación. Si dicho tenedor de la posesión de ninguna manera se ve inmerso en la pérdida de la posesión, entonces estamos ante una primera modalidad de delitos patrimoniales de sustracción. Pertenecen aquí los clásicos casos de (simple) hurto: por ejemplo, si el hipotético cliente, aprovechando una ausencia momentánea del vendedor, se lleva de la tienda el panecillo de forma subrepticia. Si, por el contrario, el tenedor de la posesión se halla inmerso de alguna manera en la pérdida de la posesión, pero su participación adolece de algún defecto de imputación, entonces el carácter de delito patrimonial de sustracción deriva, por una parte, de cuál sea el género de ese defecto de imputación y. por otra, de si ha de hacerse responsable al autor - y entonces, cómo- del defecto de imputación. Para decidirlo resulta clave la diferencia entre imputación de primer nivel (al respecto, ahora núms. 1 y 2) e imputación de segundo nivel (al respecto, núms. 3 y 4 siguientes).

1) Se excluye la imputación ordinaria de la pérdida de la posesión —en el primer nivel de imputación - en primer lugar si al tenedor de la posesión, estando allí presente, quizá incluso pudiendo observar cómo le quitan sus cosas, le resulta físicamente imposible su intervención debido a las circunstancias exteriores. Así, cuando el panadero está encerrado en la trastienda mientras le vacían el comercio. Casos de esta clase se corresponden con los más arriba designados como de necessitas simplex seu absoluta.

2) Se excluye la imputación ordinaria de la pérdida de la posesión — de nuevo, en el primer nivel de imputación - además, si el tenedor de la posesión contribuye en la pérdida de la posesión de sus cosas - por medio de un hacer o de un tolerar-, pero desconoce que le quitan las cosas y en consecuencia tampoco conoce que está contribuyendo a ello. Así, cuando el panadero ayuda al hipotético buen cliente a llevarse una bolsa con mercancías, sin darse cuenta de que son suyas (del panadero), y que el cliente en secreto ha metido en su bolsa. O también, cuando el panadero no impide, aunque en sí podría, que le quiten su mercancía porque no ha notado que alguien se las lleva. Estos casos se corresponden con los de una ignorantia facti.

${ }^{25}$ Cfr. LACKNER, § 242, núm. marg. 14. 
3) Puede excluirse la imputación ordinaria de la pérdida de la posesión —ahora, en el segundo nivel de imputación - también si el tenedor de la posesión contribuye a transmitirla - por medio de un hacer o de un tolerar-, e incluso conoce además que está contribuyendo a transmitir la posesión. De entrada esto es válido si el tenedor de la posesión se encuentra en una situación de necesidad de la clase de una necessitas cum adiunctione y entrega la cosa a causa de esta situación. Pertenecen aquí los casos de extorsión [Sacherpressung]: por ejemplo, el autor amenaza con desvelar algo comprometedor induciendo así a la víctima a pagar el precio de su silencio. También entran aquí casos como el analizado en la sentencia BGHSt. 7, 197: la autora, a raíz de una rela-ión amorosa con su cuñado durante la guerra, había tenido un hijo, y para ocultar la relación a la familia designó como padre a un conocido caído en batalla; más tarde explicó al cuñado, faltando a la verdad, que el supuesto padre regresaba, y exigía un precio por guardar silencio; si no, lo revelaría a la familia del cuñado; a consecuencia de ello, éste pagó el dinero exigido por mantener el sile.rcio ${ }^{26}$. En el ejemplo de la amenaza, como en el del BGH, la víctima se halla en una situación de necesidad que conduce a que respecto al pago del precio del silencio no sea posible la imputación ordinaria a la víctima en el segundo nivel de la imputación.

4) Se excluye la imputación ordinaria de la pérdida de la posesión — de nuevo, en el segundo nivel de imputación - además, si el tenedor de la posesión entrega la cosa desconociendo que está sufriendo una pérdida patrimonial. Si se es consecuente, entonces estos casos corresponden a la categoría de los supuestos de una ignorantia iuris; la víctima es vencida por un error, pero no sobre la cualidad de su propia conducta - la pérdida de la posesión-, sino sobre su valoración. Pertenecen a éstos los casos de estafa sobre cosas, como el clásico de la estafa de consumición , pero también es ejemplar el siguiente: el cajero del banco abona, con plena conciencia de lo que hace, 2000 marcos a quien presenta un cheque al portador, sin darse cuenta de que está librado sólo por 200. Hay que partir además de que el portador presenta el papel sin engañar al cajero sobre lo elevado del importe; y de que un "engaño por omisión» quedaría excluido por la falta de un deber de garante. Únicamente se aprovecha del error del cajero $^{29}$. La víctima se encuentra, no sólo en el ejemplo de la estafa, sino también en este último caso, en un error que da lugar a que la disposición patrimonial

${ }^{26}$ El caso no constituye un supuesto de extorsión, porque la autora no «amenazó» en sentido técnico al cuñado sino que le "previno". Sólo constituye una "amenaza" el anuncio de un mal cuya realización se debe a la influencia del que amenaza.

27

En el caso del BGH, porque el cuñado creyô en la veracidad del aviso.

${ }^{28}$ El autor engaña al camarero sobre la capacidad patrimonial para el pago de su consumición, por lo que el camarero le sirve lo solicitado.

${ }^{29}$ Por eso no se trata de una estafa sobre cosas, aunque el error del cajero hace que la entrega del dinero no sea plenamente imputable. 
por ella realizada no le sea imputable de forma ordinaria en el segundo nivel de la imputación.

¿Cómo enjuiciar los casos de estos cuatro grupos? En los casos de los grupos 1) y 2) el autor comete un hurto. Para fundamentarlo resulta decisivo que la pérdida de la posesión no puede imputarse a la víctima ya en el primer nivel de la imputación. Además es suficiente con que quede excluida la imputación ordinaria. Ello no depende de si la pérdida de la cosa puede quizá ser imputada a la víctima de forma extraordinaria. El hecho sigue siendo hurto también si el panadero no puso suficiente atención sobre sus panecillos.

En los casos de los grupos 3) y 4), por el contrario, la víctima contribuye en la traslación de la posesión consciente y con volición. La imputación en el primer nivel de la imputación no se excluye. $Y$, precisamente por este motivo, la realización de la traslación de la posesión por el autor, no es un hurto en el sentido técnico del § 242 StGB. En su lugar, entran en consideración el tipo de la extorsión (sobre cosas) para los casos del grupo 3) y el de la estafa (sobre cosas) para los del 4). De nuevo es suficiente con que quede excluida la imputación ordinaria (ahora, en el segundo nivel); y, de nuevo, ello no depende de si la pérdida de la cosa puede eventualmente imputarse a la víctima de forma extraordinaria ${ }^{30}$.

Lo mismo puede expresarse también mediante una contraposición de las ideas de "con volición» y "voluntariamente», una terminología que en la actual discusión jurídico-penal sobre los conceptos de extorsión y estafa juega ya un relevante papel. La víctima del hurto no contribuye en la traslación de la posesión "con un acto de volición", mientras que la víctima de la extorsión o de la estafa sí lo hace "con un acto de volición». Sin embargo, el extorsionado bajo el influjo de coacción no actúa "voluntariamente», como tampoco la víctima de una estafa actúa en cierto sentido "voluntariamente». Así como el panadero que desconoce la prohibición de trabajar de noche elabora "voluntariamente» sus panecillos, pero no actúa "voluntariamente» contra la prohibición, también la víctima de la estafa contribuye "voluntariamente" en el desplazamiento de la posesión, pero no actúa "voluntariamente» contra los criterios de lo razonable en términos económicos - como podría decirse, y luego se hará alusión a ello-.

La distinción entre hurto y extorsión desde el punto de vista de la imputación proporciona también claros $\mathrm{y}$, sobre todo, comprensibles criterios para distinguir entre robo y extorsión agravada [räuberische Erpressung, sancionada como robo], cosa que no permite la actual situación legal. Así, si el autor ha generado la situación de

${ }^{30}$ Sobre la posibilidad de que la conducta imprudente de la victima tenga relevancia sobre nuestro juicio del hecho del autor, cfr. Manfred ElLMER, Betrug und Opfermitverantwortung, Berlin, 1986, passim. 
necesidad (la necessitas simplex seu absoluta) en la que se encuentra la víctima en los casos del grupo 1), y la emplea como medio para quitarle las cosas, entonces el hurto pasa a ser robo. Esto presupone, claro está, que el autor emplea violencia y que ésta debe ser una vis absoluta. Una vis compulsiva o una intimidación nunca pueden llevar a una situación de necessitas absoluta. Pero si esto es correcto, entonces no hay lugar en el actualmente vigente $\S 249$ StGB [robo] para un robo intimidatorio mediante peligro actual para la vida o integridad". En este sentido, la ley incurre en un error y debe modificarse en este aspecto. En cambio, en los casos del grupo 3), vis compulsiva e intimidación pueden emplearse con un peligro actual para la vida o la integridad como medio para conseguir una disposición patrimonial. Ambas transforman una extorsión en una extorsión agravada [räuberische Erpressung, sancionada entonces como robo]. No puede darse una extorsión agravada en la que el empleo de violencia constituya ya una vis absoluta. Cualquier hipótesis contraria disuelve el sistema.

Pero siendo así, no todos los casos incluidos en la categoría 3) son casos de extorsión: por ejemplo, no lo es el caso enjuiciado en BGHSt. 7, 197. Como tampoco todos los casos de la categoría 4) son supuestos de estafa: por ejemplo, no lo es el caso tratado más arriba del cajero del banco. En general, pertenecen a la categoría 3), pero no constituyen casos de extorsión ni aquellos supuestos en los que el autor genera la situación de necesidad que entonces aprovecha para lograr sus objetivos, aunque no aplicando violencia o intimidación, sino de otro modo (así, en el caso del BGH, donde lo que hace es "prevenirle»), ni aquéllos en los que el autor aprovecha una situación de necesidad que existe con independencia de él. $Y$ paralelamente, pertenecen a la categoría 4), pero no constituyen casos de estafa ni aquellos supuestos en los que el autor genera el error relevante de la víctima que entonces aprovecha para lograr sus objetivos, aunque no por medio de un engaño, sino de otro modo, ni aquéllos en los que el autor aprovecha un error que existe con independencia de él. En ello estriban en parte las dificultades que la dogmática jurídico-penal actual encuentra en el $\S 253$ [extorsión] y, en especial, en el $\S 263$ [estafa] StGB. Ante todo, lo que hay que hacer al enfrentarse con el texto de la ley en esta materia es obrar con honradez y reconocer que hay lagunas de punibilidad, y no intentar cubrir dichas lagunas (real o de forma hipotética) mediante cuestionables «interpretaciones» de la ley.

Las dificultades con los actuales $\S \S 242,253$ y 263 StGB estriban sobre todo según entiendo- en que la cuestión decisiva todavía no ha sido ni siquiera planteada.

\footnotetext{
"Cfr. en nota 5 el texto del $\S 249$ I. Partiendo de que el robo violento es tal porque la sustracción se produce mediante vis absoluta que excluye la imputación del primer nivel, no cabe robo violento mediante una situación de vis compulsiva o amenaza (segundo nivel). La regulación española del robo violento e intimidatorio (arts. 237 y 242 CP) podría encontrar aquí también un motivo para distinguir el tan tradicional binomio conceptual de la "violencia e intímidación", aceptando que bajo dicha denominación a menudo se consideran casos de muy diversa entidad: unos supuestos (robo violento) que excluyen la imputación de primer nivel, y otros (robo intimidatorio y mediante vis compulsiva) que excluyen la del segundo nivel (N. del T.).
} 
La base de partida es la determinación de que la exclusión de la imputación en todos los casos de los grupos 3) y 4) no tiene lugar en el primer nivel. Ahora bien, si es así, la cuestión de si la imputación en el segundo nivel debe excluirse o no, supone aceptar por parte de quien se la plantea que ya ha sido aplicado un sistema de reglas, en atención al cual puede hablarse con toda razón de una imputación y una exclusión de la imputación. La cuestión implica dicha aceptación, del mismo modo que toda imputatio iuris implica una applicatio legis ad factum. Cuando tratamos de la imputación de segundo nivel, buscamos con ello el sistema de reglas que ya venimos aplicando (intuitivamente) al hacer o tolerar de la víctima que ha contribuido en la traslación de la posesión. Tal vez habría que pensar en las reglas que un sujeto racional sigue al actuar en el campo de la Economía. Sólo en atención a tal sistema de reglas cabe plantear con rigor las cuestiones que se suscitan en relación con las ideas de extorsión sobre cosas y estafa sobre cosas. Nos encontramos así ante la tarea de elaborar dicho sistema de reglas, una tarea que en este lugar sólo puede plantearse, pero no resolverse. 